\title{
P-0921 Cardiovascular risk in subjects with diabetes (aged 40-79 years) from Romania
}

M.M. Rosu ${ }^{1}$, A. Popa ${ }^{1}$, S.G. Popa ${ }^{1}$, D. Protasiewicz ${ }^{1}$, A.G. Firanescu ${ }^{1}$, M.L. Bicu², E. Mota ${ }^{1}$, M. Mota ${ }^{1}$.

${ }^{1}$ Clinical County Emergency Hospital Craiova, Craiova, Romania.

${ }^{2}$ Filantropia Hospital, Craiova, Romania.

Background - Diabetes mellitus (DM) and atherosclerotic cardiovascular diseases (ASCVD) are two of the most common chronic non-communicable diseases, having a very high prevalence worldwide.

The aim of this study was to estimate the cardiovascular risk (CVR) in Romanian adults with DM.

Method: This study was part of PREDATORR study (PREvalence of DiAbeTes mellitus, prediabetes, overweight, Obesity, dyslipidemia, hyperuricemia and chronic kidney disease in Romania), an epidemiological study that had a stratified, crosssectional, cluster random sampling design, including 2729 subjects aged between 20 and 79 years.

Inclusion criteria were: age over 40 years old with DM, no personal history of peripheral vascular disease, cerebrovascular disease, CHD, MI, coronary revascularization.

The CVR was evaluated using the charts proposed by the WHO/ISH available for Europe B (epidemiological sub-region which includes Romania). According to the calculated 10 years CVR the study population was divided into 5 categories: $<10 \%, 10-20 \%, 20-30 \%, 30-40 \%,>40 \%$.

Bias site selection was excluded through weighting, the sample being adjusted in order to extrapolate the results to the data reported at the last Romanian census published in 2011. Statistical analysis was performed using SPSS 20.0

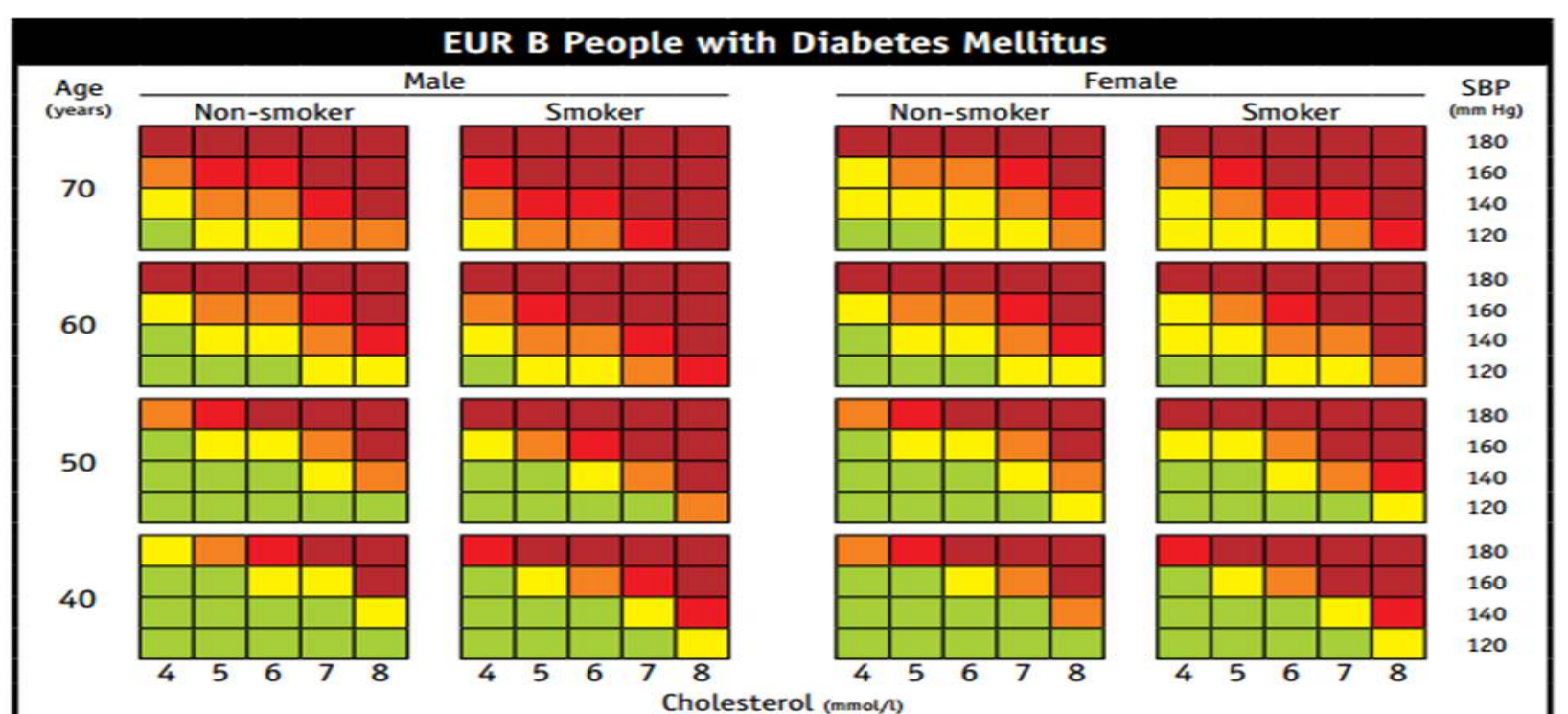

Results:

A total of 243 subjects ( $52.7 \%$ males and $47.3 \%$ females) met the inclusion criteria.

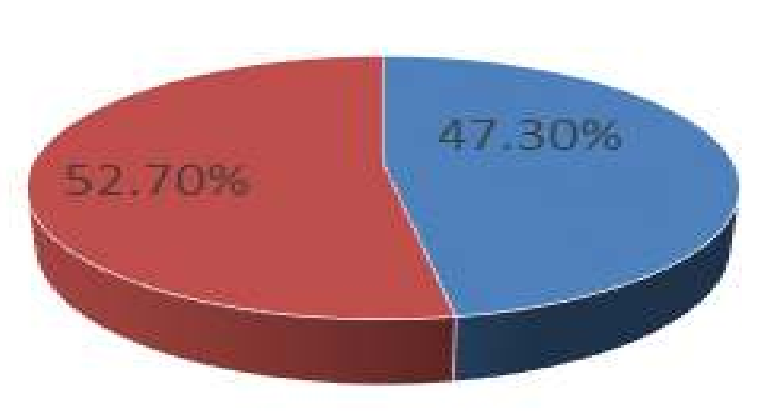

- Women = Men
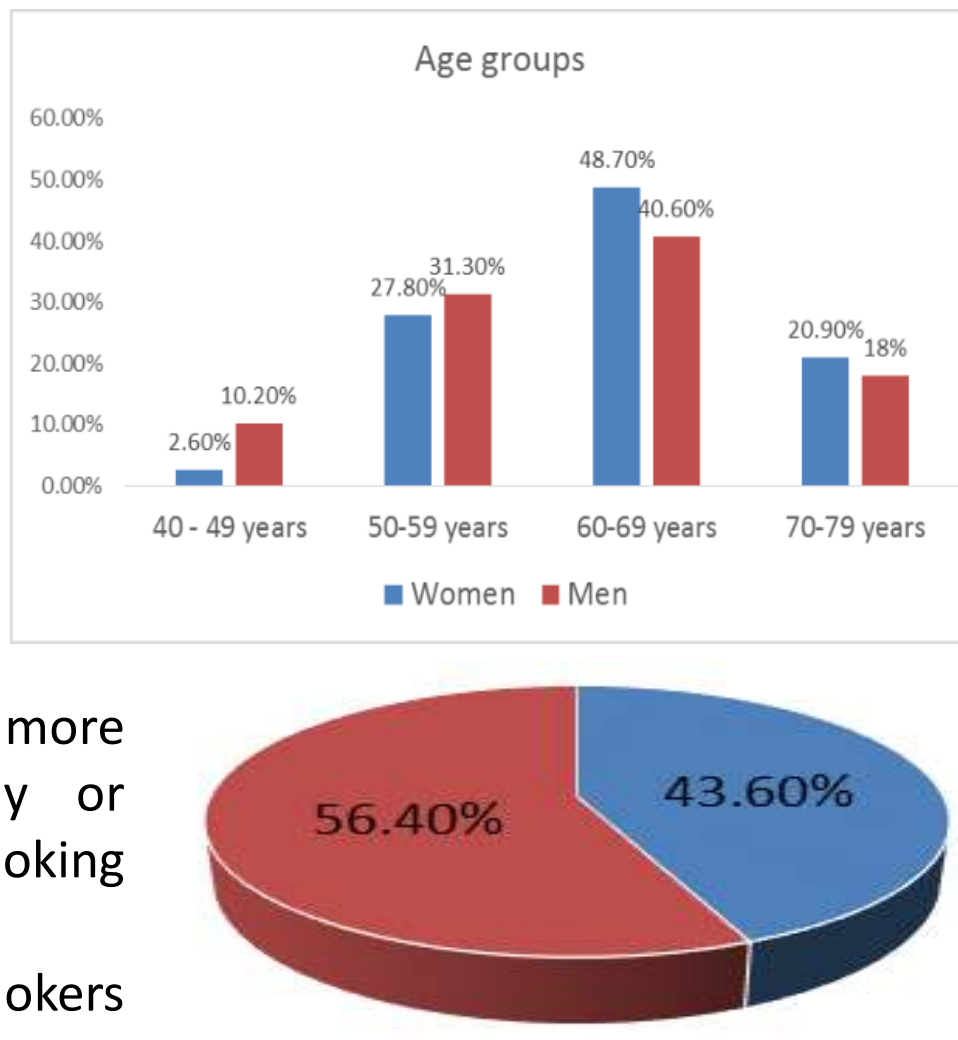

- Smokers - Non-Smokers
Smokers - Subjects who smoke more than one cigarette daily, daily or occasionally, or who have quit smoking for less than a year.

Non-smokers - non-smokers or smokers who have quit for more than a year.

$\mathrm{mmHg} / \mathrm{or} \mathrm{DBP} \geq 90 \mathrm{mmHg}$ or -Subjects with HBP - SBP $\geq 140 \mathrm{mmHg} /$ or $\mathrm{DBP} \geq 90 \mathrm{mmHg}$ or
antihypertensive treatment or personal history of hypertension -Subjects without HBP - SBP $<140 \mathrm{mmHg} /$ or DBP $<90 \mathrm{mmHg}$ without antihypertensive treatment and without personal history of hypertension.

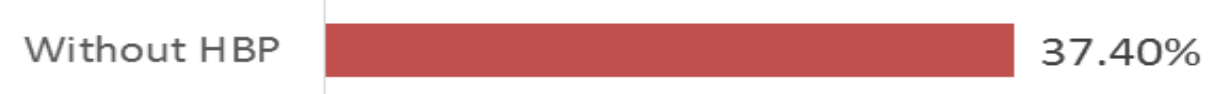

With HBP

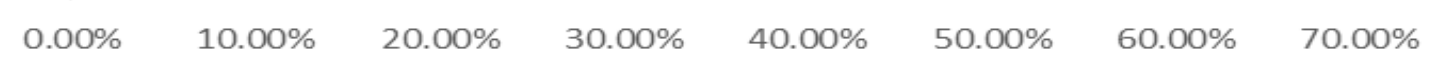

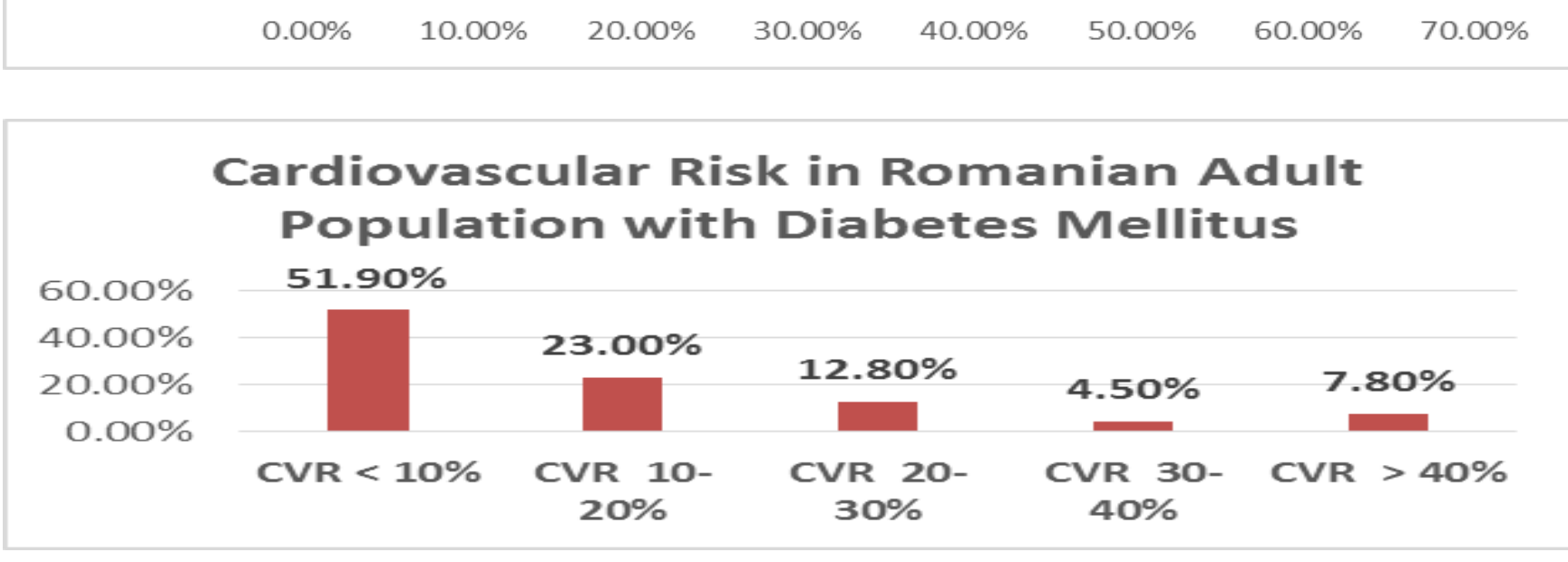

Discussion: Our study found a very high CVR in Romanian subjects with DM, confirming the need to develop and implement diabetes and ASCVD prevention programs in order to decrease the prevalence of these two disorders.

\section{CARDIOVASCULAR RISK IN ROMANIAN ADULT POPULATION WITH DM (BY AGE GROUP)}

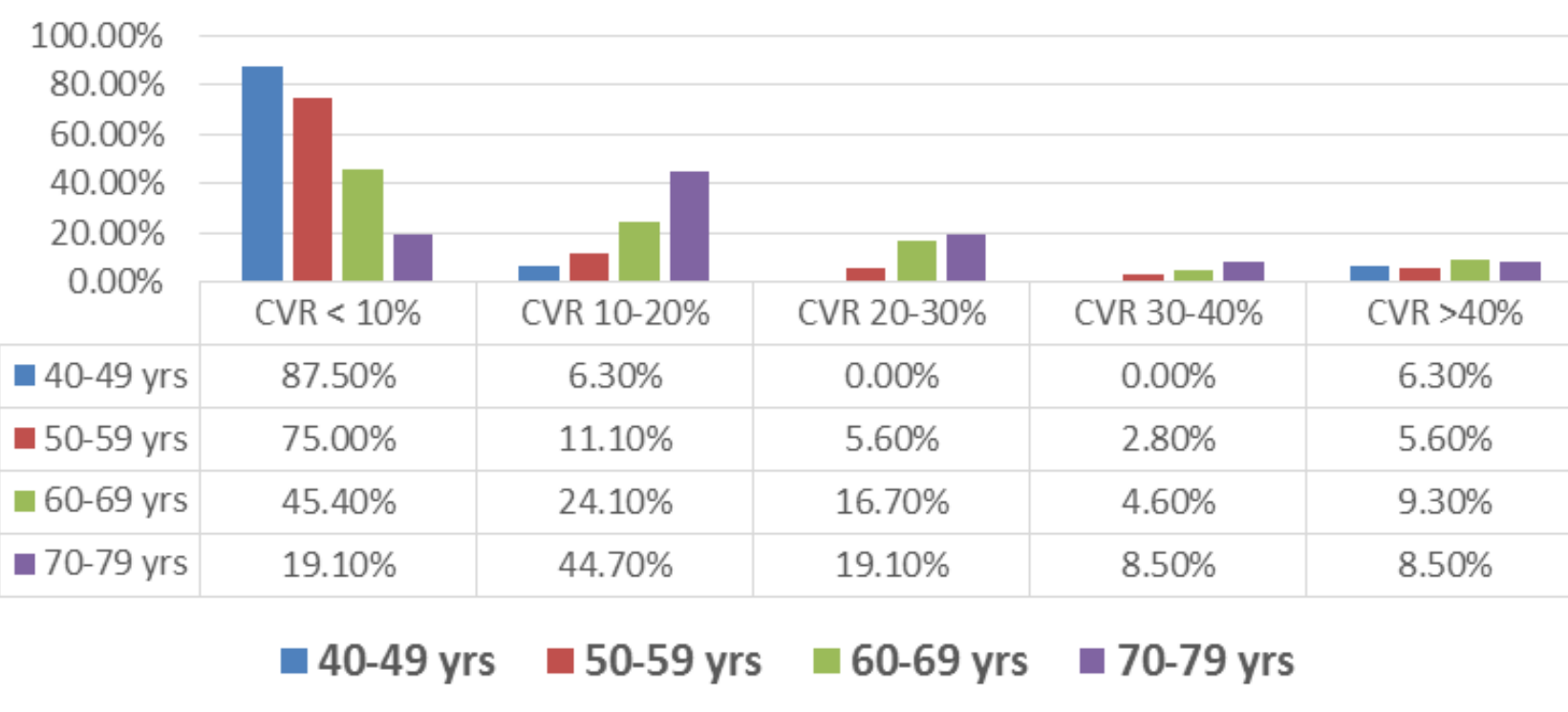

Furthermore, the CVR increased with age, the greatest risk being in the age group $70-79$ years.

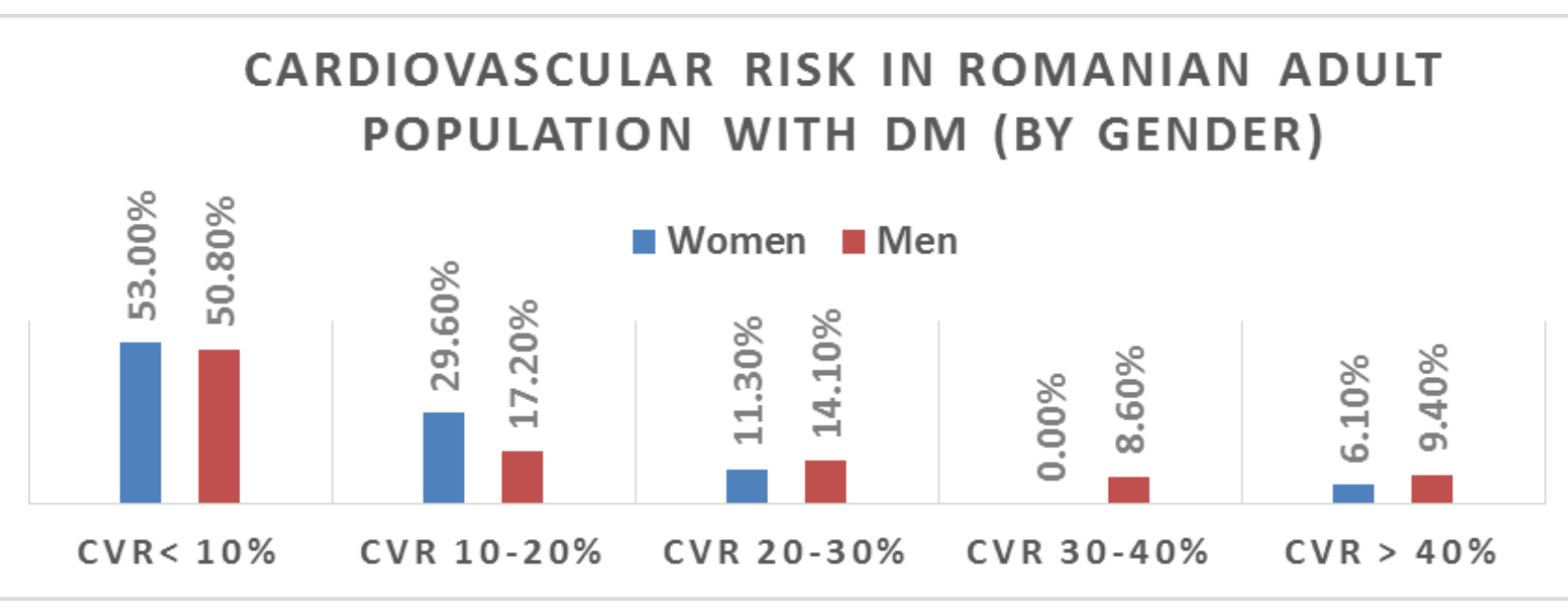

The CVR was significant higher in men.

CARDIOVASCULAR RISK IN ROMANIAN ADULT POPULATION WITH DM (BY SMOKING)

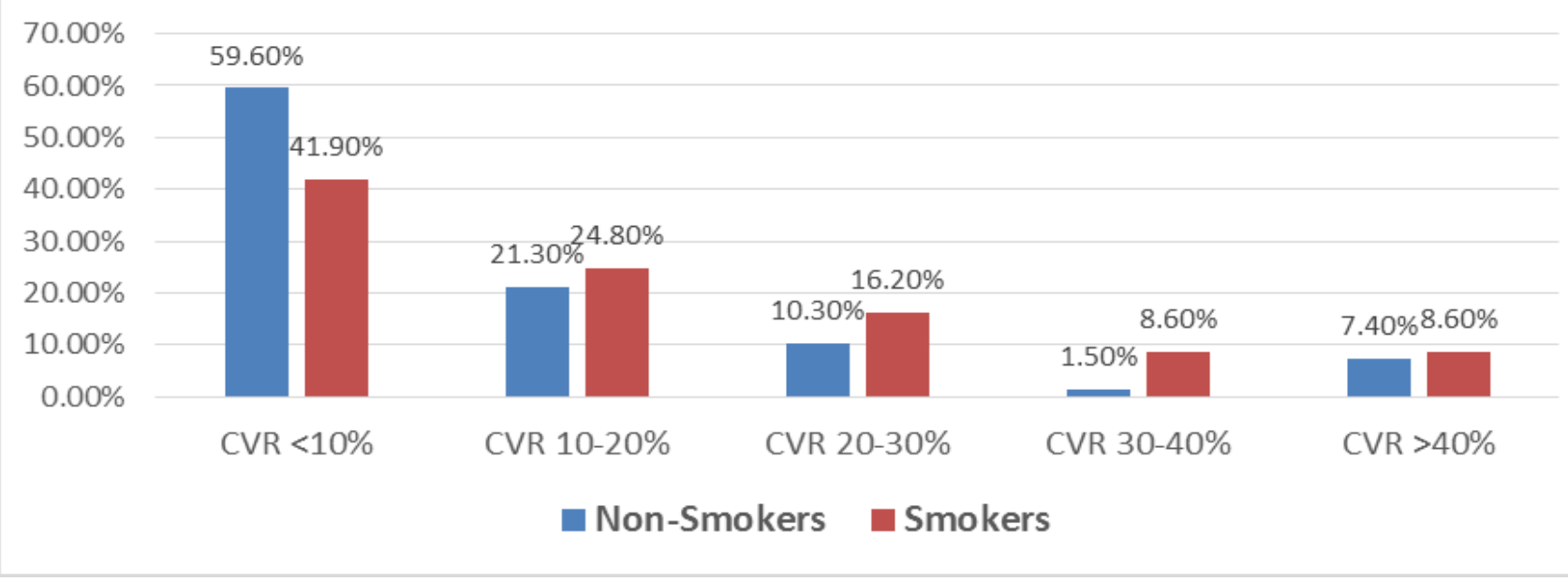

Smokers also had a higher CVR compared to non-smokers.

\section{CARDIOVASCULAR RISK IN ROMANIAN ADULT POPULATION WITH DM (BY HYPERTENSION)}

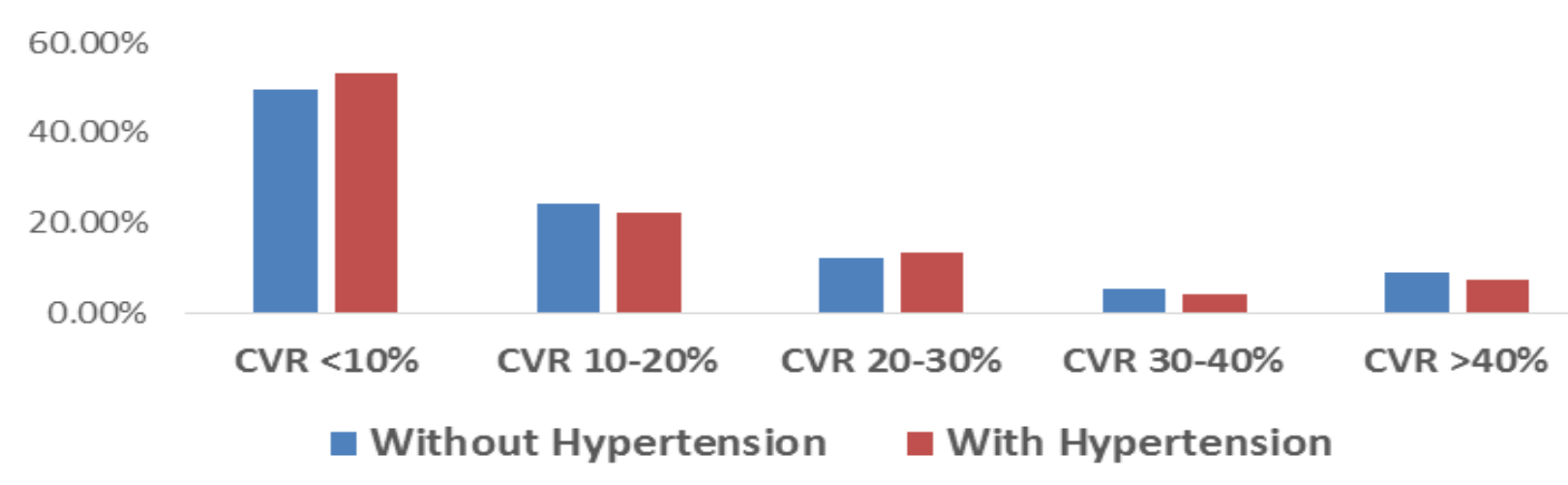

Subjects with hypertension had a significantly lower CVR than the subjects without hypertension. 